\begin{tabular}{c} 
Volume and Issues Obtainable at Center for Sustainability Research and Consultancy \\
Responsible Education, Learning and Teaching in Emerging Economies \\
ISSN: 2708-4310 (E): 2708-4183 \\
Volume 1: No. 2, December 2019 \\
CSRᄃ \\
Journal homepage: www.publishing.globalcsrc.org/relate \\
\hline
\end{tabular}

\title{
Gender Differences in Students' Interpersonal Communication
}

\author{
${ }^{1}$ Emma Dwi Ariyani, ${ }^{2}$ Dini Hadiani \\ ${ }^{1}$ Lecturer, Department of Manufacturing Engineering, Politeknik Manufaktur Bandung, Indonesia: \\ emma@polman-bandung.ac.id \\ ${ }^{2}$ Lecturer, Department of Design Engineering, Politeknik Manufaktur Bandung, Indonesia: \\ dinibhs@polman-bandung.ac.id
}

\begin{tabular}{l}
\multicolumn{1}{c}{ ARTICLE DETAILS } \\
\hline History \\
Revised format: November 2019 \\
Available Online: December 2019 \\
\\
Keywords \\
Interpersonal Communication, \\
Gender Differences, Empathy, \\
Positive Attitude
\end{tabular}

\section{JEL Classification:}

L63, L69

\section{ABSTRACT}

Objective: Interpersonal communication is an essential element of communication that creates meaningful social relationships in the academic environment. Students who have good interpersonal communication skills will be capable of interacting with others. However, it was reported that some students still have a low capacity for interpersonal communication caused by various factors, and one of them is gender. This research attempts to investigate the students' interpersonal communication concerning gender and to find out whether there is a difference between male and female students in terms of interpersonal communication.

Methodology: This study was conducted through a descriptive method. The subject of this study includes 88 students consisting of 66 male and 22 female students at one state polytechnic in Bandung, Indonesia. The data were collected in terms of interpersonal communication and gender.

Results: The results show that male students had a slightly higher score of interpersonal communication than females. Regarding the significant elements of effective interpersonal communication, it was found that there are differences in the dominant component of interpersonal communication between male and female students. Female students dominated the area of equality, indicating that they have a more dominant ability to position themselves as equivalent to their communication partners to create comfortable communication. Male students dominated the area of openness, empathy, supportiveness, and a positive attitude showing that they have a more dominant ability to show a willingness to communicate honestly and full of understanding, so they were able to give support and positive thought.

Implication: The study recommends the use of appropriate communication activities that can encourage the students to be open, to be supportive, and to be positive. This condition will enable teachers to choose and apply the appropriate methods in the teaching and learning process to support the development of students' interpersonal communication.

\section{OPEN ACCESS}

(C) 2019 The authors, under a Creative Commons AttributionNonCommercial 4.0 
Recommended citation: Ariyani, E. D. \& Hadiani, D., (2019). Gender Differences in Students' Interpersonal Communication. Responsible Education, Learning and Teaching in Emerging Economies, 1(2), $67-$ 74

DOI: $10.26710 /$ relate.v1i2.1125

\section{Introduction}

Students require more practical and more profound knowledge about the subject they are learning in school and college. It can be accomplished through several processes, including effective interpersonal communication. Interpersonal communication is a process of sending and receiving messages that are used to produce meaning between two or more people with effects and feedbacks to be mutually beneficial to talk and listen (DeVito, 2009; Pearson et al., 2011). This type of communication pattern is considered as an essential element in social activities that students will get involved in the academic environment. Therefore, students who have excellent interpersonal communication skills will be easy to get along with others as effective interpersonal communication can create an environment that is full of pleasure and understanding towards better relations between students (Anggeraini and Farozin, 2019). It indicates that students are required to have excellent interpersonal communication to be successful during their studies.

Ariyani (2013) and Sadikin et al. (2016) investigated the general description of the soft skills index of vocational higher education students in Indonesia. The results showed that students' communication skills are considered as the lowest aspect compared to the other elements such as motivation, flexibility, willingness to learn, integrity, relationship building, teamwork \& cooperation, and leadership. This evidences that communication skill is the ability that should be improved, and it can be performed by developing the students' interpersonal communication.

Many studies of students' interpersonal communication have been performed in various types of fields (Amiruddin and Nor, 2014; Sari, 2018; Anggeraini and Farozin, 2019; Phulsunge and Kalbonde, 2019). The results of the studies show that interpersonal communication in engineering education is importance that it should be enhanced to make the students employable (Phulsunge and Kalbonde, 2019) since there are still many students who had low interpersonal communication skills (Anggeraini and Farozin, 2019), even though there is no direct relationship between demographic factors such as gender, age and length of service in influencing the Interpersonal Communication Skills (Amirudin and Nor, 2014). The problems encountered by students related to the low capacity of interpersonal communication can be solved by involving students in a communication setting in the form of role-playing (Sari, 2018).

However, the majority of the previous studies examined interpersonal communication as a general concept, while essential characteristics such as gender were ignored. With the increasing gender issues appear these days, it is necessary to investigate the students' interpersonal communication in different gender, respectively. It is argued that females are more likely than males to have self-disclosure both in face to face and email communication ( $\mathrm{Yu}, 2014)$. It is also stated that both men and women communicate in particular ways, which are associated with their gender (Tannen, 1991). Male use conversation to establish status and power, which belongs to a "report" type talk. While women tend to use conversation to create intimacy, which is considered as "rapport" type talk (Tannen, 1991). A study conducted by Debrand and Johnson (2008), on the contrary, states that men and women perceived similar recognition towards email or instant messaging during communication. Taken these phenomena into consideration, it is, therefore, necessary to explore the students' interpersonal communication based on gender perspective to find out whether there is a difference between male and female students. It attempts to study the elements of effective interpersonal communication, i.e., openness, empathy, supportiveness, positive attitude, and equality. Having good interpersonal communication will make students establish communication and socialize with their friends. This condition will lead them to be successful in their studies. The results are supposed to contribute to the study of interpersonal communication in terms of gender. Furthermore, the information in this study can be a guidance for future researches on the same 
interest.

\section{Interpersonal Communication}

Interpersonal communication can be defined as a process of sending and receiving messages that are used to produce meaning between two or more people with effects and feedbacks to be mutually beneficial to talk and listen (DeVito, 2009; Pearson et al., 2011). Effective interpersonal communication is expected to create an environment that is full of pleasure and understanding of better relations between students (Anggeraini and Farozin, 2019). Some purposes of interpersonal communication are to learn, to relate, to influence, to play, and to help you to better understand the external world, the world of objects, events, and other people (DeVito, 2009). Some purposeful of interpersonal communication above can make our relationship with each other to be harmony and to be better understood by each other. Interpersonal communication has a function that can make process communication more comfortable to understand by the listener when all of the purposeful used well. For students, having good interpersonal communication is important since they have to interact with their friends during their studies. If they have a low capacity in interpersonal communication, it will make them difficult to get adapted to the academic environment, and it will lead them to failure in their study.

Interpersonal communication is stated to be effective when it is fun for the communicant. Effective interpersonal communication includes openness, empathy, supportiveness, positive attitude, and equality. The elaboration of each criterion is as follows DeVito (1997).

- Openness. Openness is often defined as someone's ability to accept input from others and to be pleased to convey important information to others. This criterion will be valid if the communicators are open to the person to whom they interact. They also should have a willingness to react to any situation honestly, and they should always concern the "ownership" of feelings and thoughts.

- Empathy. Empathy is a person's ability to feel what another person can understand something that is being experienced by others, can feel what others think, and can sense some issues from the perspective of others, through the eyes of others. Empathy can be transmitted, both verbally and non-verbally, in which non-verbal one is usually exhibited through facial expressions and gestures, eye contact, posture attentive, and physical proximity.

- Supportiveness. An effective interpersonal relationship requires a supportive attitude. It means that each party is committed to supporting the implementation of open interaction.

- Positive. A positive attitude is displayed in the form of attitudes and behavior. The sides involved in interpersonal communication must experience feelings and positive thoughts, not prejudice and suspicion.

- Equality. Equality is a mutual understanding that both parties have an interest, and they are equally valuable and precious, and each requires the intention of equality here is the recognition or awareness.

\section{Interpersonal Communication in Gender Perspective}

Excellent communication is a challenging skill to master and may create problems. Several factors, such as the situation, time, cultures, and gender styles, may affect the process of communication. Gender differences may exist due to genetic differences, cultural exchange, behavioral expectations, and training.

Many things may influence people's communication styles, which cover their origin, the method of how they were raised, educational background, age, and also gender. In general, men and women talk differently and in particular ways. These differences are usually associated with their gender. Male and female brains have a different structure to process information differently (Tannen, 1991). In many cases, men analytically process the information while women abstractly handle things. Each gender is considered a distinctive communication pattern, and it often causes problems as it is always assumed that different gender may think and act similarly. They feel that they are using a similar pattern of 
communication, but obviously, they are not.

Males and females are distinguished based on their communication patterns (Tannen, 1991). It was found that males use conversation to establish status and power, which belongs to a "report" type talk, while women tend to use conversation to create intimacy, which is considered as "rapport" type talk (Tannen, 1991). Therefore, the male performs competitive conversation, while the female presents a more cooperative one. In terms of problem-solving, males share a direct approach, while females tend to establish intimacy, show concern, and empathy. When it is related to the order of thinking, males look for solutions, and they often utilize their power to accomplish the problem-solving task while females usually use problem-solving to strengthen relationships. In general, male performs a higher percentage of presenting information, giving direction, providing answers, and direct disagreement than female do (Tannen, 1991)

\section{Methods}

The descriptive method is employed to describe a state at the time of research. This research uses a set of questionnaires to view the interpersonal communication of students, both male and female.

\subsection{Participants}

The participant of the research is the students of one state vocational higher education in Bandung, Indonesia. The purposive sampling is used in the process of selecting the subject that complies with the best position to support the required information. The subjects of this study are students of grades I, II, and III, as many as 88 students, consisting of 66 males and 22 females in the range of 18 to 20 years old. The description of subjects can be seen in the following tables.

TABLE I. DESCRIPTION OF SUBJECTS BASED ON GENDER

\begin{tabular}{|l|l|l|}
\hline Quantity & Sex & Percentage \\
\hline 66 & Male & $75 \%$ \\
\hline 22 & Female & $25 \%$ \\
\hline 88 & Total & $100 \%$ \\
\hline
\end{tabular}

TABLE II. Description Of Subjects Based On Level Of Study

\begin{tabular}{|c|c|c|c|}
\hline Year & I & II & III \\
\hline Male & 10 & 16 & 40 \\
\hline Female & 2 & 2 & 18 \\
\hline Quantity & 12 & 18 & 58 \\
\hline Percentage & $14 \%$ & $20 \%$ & $66 \%$ \\
\hline
\end{tabular}

\subsection{Data collection method and Data Analysis}

The questionnaires were developed based on DeVito's $(1997,2009)$ criteria of effective interpersonal communication, which consists of 40 statements to measure the students' interpersonal communication in terms of openness, empathy, supportiveness, positive, and equality based on gender perspective (Tannen, 1991). Example items used in this study are: "I accept advice from my friends" and "I'm a good listener whenever my friends tell me about their problems." Subjects are asked to give a mark on one of the columns ranging from 'strongly disagree' up to 'strongly agree.' The completed questionnaire was then 
pilot tested among students who were not the participants of this study. It can be declared that the instrument is valid and reliable. The data analysis technique uses the average value of the total score on each category of interpersonal communication to find out the difference between male and female students. The data obtained from the students' interpersonal communication were then matched with the theory of gender communication.

\section{Results and Discussion}

This section attempts to describe the interpersonal communication based on gender perspective in vocational higher education students and to elaborate on whether there are differences in terms of effective interpersonal communication covering the openness, empathy, supportiveness, positive attitude, and equality between male and female students. The result found that male students (3.17) had a little higher average score of interpersonal communication than female students (3.13), so that it showed the general picture of the students' interpersonal as seen in table 3 below.

TABLE III. Description Of Students Interpersonal Communication Based On Gender

\begin{tabular}{|l|l|l|}
\hline $\begin{array}{l}\text { Interpersonal } \\
\text { Communication }\end{array}$ & Female & Male \\
\hline Openness & 2.86 & 3.00 \\
\hline Empathy & 3.21 & 3.34 \\
\hline Supportiveness & 3.15 & 3.16 \\
\hline Positive & 3.17 & 3.18 \\
\hline Equality & 3.26 & 3.18 \\
\hline Average & 3.13 & 3.17 \\
\hline
\end{tabular}

Based on the findings shown in Table 3 above, it can be interpreted that male students have a slightly higher score of interpersonal communication than female students. This information indicates that male students tend to be a good communicator that can maintain the meaningful environment of communication compared to female students. Surprisingly, it is not in line with the finding of another study stating that females are likely than males to have self-disclosure in interpersonal communication (Yu, 2014). This phenomenon is probably due to differences in the background of the study participants, such as several samples, age, environment, and culture, where the current research is conducted.

Each category of effective interpersonal communication is then examined more in some depth. The results of the average score of each group of effective interpersonal communication on both male and female students can be seen in Tables 4 and 5 below.

TABLE IV. Description Of A Score Of Interpersonal Communication On Female Students

\begin{tabular}{|c|c|c|c|c|}
\hline Openness & Empathy & Supportiveness & Positive & Equality \\
\hline 2.86 & 3.21 & 3.15 & 3.17 & 3.26 \\
\hline
\end{tabular}

TABLE V. Description of A Score of Interpersonal Communication on Male Students 


\begin{tabular}{|c|c|c|c|c|}
\hline Openness & Empathy & Supportiveness & Positive & Equality \\
\hline 3.00 & 3.34 & 3.16 & 3.18 & 3.18 \\
\hline
\end{tabular}

Based on data in table 4 about the score of interpersonal communication on female students, it shows that female students have a higher score on the equality category (3.26). It can be said that female students have a more dominant ability to put themselves in equal manners. They show a willingness to put themselves as equivalent to the communication partner. Thus it shows that they were aware of the importance of being different, and they recognized the importance of the presence of others, so they were able to create two-way communication with mutual need and comfortable communication. It indicates that female students were able to treat people equally, not to mention their different gender. This could be influenced by the raising issue of gender equality, in which both males and females are positioned on the same level. This finding is in line with the theory proposed by Tannen (1991), stating that females can make a connection and to create intimacy during communication.

In terms of the score of interpersonal communication on male students, it is shown in table 5 that they dominate more categories of effective interpersonal communication than female students. Male students have a higher score of openness category (3.00). It indicates that they have a more dominant ability to show that they are open to accepting input from others and try to convey important information to others. Surprisingly, this is not in line with Tannen's (1991) proposition claiming that males use conversation to be more competitive to show their power and status. It may happen due to the male students' motivation that leads them to trust their communication partner so that they could be open to them. This circumstance is considered good since having the ability to be able to accept input from others can make the students more comfortable to deal with the academic challenges they face during their study. Female students, on the other hand, tend to be shy in becoming open to their friends, so they limit their talk to their friends only about things in general. This problem can be solved by giving several communication activities to them, showing them that becoming open and accepting input from others are useful to help them improve both their technical and nontechnical skills. This idea is in line with Sari's (2018) suggestion that students can be supported to develop their interpersonal communication by involving them in several communication activities, such as role-playing.

Concerning the other category of effective interpersonal communication, which is empathy, it was found that male students have the highest score (3.34) compared to the other categories. Male students have a more dominant ability to feel what their friends think and understand what is being experienced so that they can understand the issue from the perspective of others. Again, surprisingly, this is not in line with Tannen's (1991) idea stating that when it comes to thinking about one issue, males expect a solution, and then they use their power to accomplish the problem-solving. On the other hand, this problem-solving issue is a way used by females to strengthen relationships, to share, and to discuss with their communication partners. This phenomenon might happen since male students have a strong motivation and confidence to build strong relationships with their friends so as they will be successful in finishing the task during their study by cooperating with others while female students seem to have low empathy due to their lack of motivation. They assume that their friends are competitors, so that they will consider them as people in general. Several explanations, communication activities, and guidance could be given to the female students to make them realize that becoming competitors does not mean that they would forget they are people who need to show empathy in any circumstance.

In terms of supportiveness, both male and female students share almost a similar score only that male students have a slightly higher score (3.16 to 3.15). The male students were able to show a supportive attitude by being descriptive, not evaluative, provisional, and very confident. They tend to support their friends during their studies, such as in finishing their tasks, male students would help their friends who had difficulties. They also tried to assist each other in understanding a subject given in the classroom. It might be generated by the male students' motivation to support their friends so that they can succeed at the same time. Female students also showed their support to their friends, although their ways are 
different from those demonstrated by male students. They tend to support their friends who had low scores on examination by helping them to understand the subject so that they could achieve the targeted score. It can be said that both male and female students were supportive of their friends through different treatments. This finding is in line with Tannen's (1991) idea that males and females have different ways of communicating with others.

Regarding the other category of effective communication, which is a positive attitude, male students have a higher score (3.18) compared to female students (3.17). Male students seemed to assume that people are kind, so they were able to appreciate the differences among them. They tend to see things from a positive perspective. This fact could mean that male students tend to show a positive attitude in the communication reflected by positive feelings and positive thoughts. While female students tend to perceive the problems that happen to them negatively, which might be caused by their lack of selfconfidence, the preferable solution is to provide guidance that can assist the students in accepting problems and giving them the motivation that their issues can be solved.

\section{Conclusion}

The study has revealed the interpersonal communication of vocational higher education students. There are two relevant findings related to gender domination in the students' interpersonal communication and the possible factors affecting the phenomena. First, in terms of gender domination in the students' interpersonal communication, the results show that male students had a slightly higher score of interpersonal communication than females. Regarding the significant elements of effective interpersonal communication, which are openness, empathy, supportiveness, positive attitude, and equality, it was found that there are differences in the dominant component of interpersonal communication between male and female students. This finding shows that female students dominated the area of equality. It can be said that female students have a more dominant ability to position themselves as equivalent to their communication partners. They were also knowledgeable of the importance of being different, but they were able to build two-way communication and mutual need for comfortable communication. Male students dominated the area of openness, empathy, supportiveness, and a positive attitude. It indicates that male students have a more dominant ability to show a willingness to communicate honestly and understand something that is being experienced by their communication partner, so they were able to give support and positive thought. Secondly, it was also found that confidence and motivation are the two possible factors affecting the students' interpersonal communication. The results of the study suggest that appropriate mechanisms should be formulated to enhance the students' interpersonal communication. It could be performed by providing several communication activities that can encourage the students to be able to accept input from others, to understand others' perspectives, to be supportive, and to always have a positive mind. Having this information can enable teachers to choose and apply the appropriate methods of teaching and learning to support the development of students' interpersonal communication. Since this study mainly concerns with a gender perspective, further research can identify the students' interpersonal communication, in terms of culture, age variation, education background, and other indicators.

\section{Acknowledgment}

This research was supported by Politeknik Manufaktur Bandung Research Grant 2019.

\section{References}

Amiruddin, M., and Nor, M. (2014). “Interpersonal Communication Skills among The Master's Students in TVET" in Developing Country Studies. Volume 4 No.16

Anggeraini, D., and Farozin, M, (2019), "Interpersonal Communication Skills and Self Confidence of Secondary School Students: Findings and Interventions" in International Conference on Meaningful Education, KnE Social Sciences, pages 140-145. 
DOI 10.18502/kss.v3i17.4633

Ariyani, E. D. (2013). Studi Deskriptif mengenai Soft Skills pada Mahasiswa di Polman Bandung. Jurnal Sosiohumaniora, 15(2), 151-157.

Debrand C.C., and Johnson, J.J. (2008). Gender Differences in Email and Instant Messaging: A study of Undergraduate Business Information System Students. Journal of Computer Information System.

Devito, J.A. (1997). The Interpersonal Communication. Published by Longman Public Group .

Devito, J.A. (2009). The Interpersonal Communication. Pearson education, America.

Pearson, J.C., Nelson, P.E.,Titsworth, S., \& Harter, L.(2011). Human Communication (4thed). New York: The McGraw-Hill Companies, Inc.

Phulsunge. S., and Kalbonde V.N. (2019). Importance of Intrapersonal and Interpersonal Skills to make Work Ready Professionals. International Journal of Management, Technology, and Engineering. Volume IX. Issue I.

Sadikin, S., Ariyani, E. D., \& Muhammad, A. (2016). Analisa Hasil Implementasi Model Pengukuran Soft Skills pada Mahasiswa Polman Bandung. Paper presented at Seminar Nasional Hasil Penerapan Penelitian dan Pengabdian Masyarakat III, Jakarta, Indonesia.

Sari, Y.N. (2018). The urgency of developing trust and interpersonal communication skills of students through role playing. Konselor, 7(3), 89-94. https://doi.org/10.24036/02018738684-0-00

Tannen, D. (1991). You Just Don’t Understand: Women and Men in Conversation. New York: Ballantine Books.

Yu, T. (2014). Gender Differences on Self-Disclosure in Face to face Versus Email Communication. International Conference on Education, Language, Art and Intercultural Communication (ICELAIC). 